\title{
B.Е. Гимпельсон
}

Центр трудовых исследований НИУ ВШЭ, ИС ФНИСЦ РАН, Москва

\author{
E.M. Чернина
}

Центр трудовых исследований НИУ ВШЭ, Москва

\section{Положение на шкале доходов и его субъективное восприятие ${ }^{1}$}

\begin{abstract}
Аннотация. Мы анализируем формирование субъективных представлений людей о том, как они видят свое место в распределении доходов, и то, как это восприятие отличается от места, зафиксированного с помощью объективных данных. Затем мы пытаемся объяснить эти смещения, уделяя особое внимание опыту мобильности, который есть у индивидов, и уровню их жизненного оптимизма. В поисках ответов мы используем данные «Российского мониторинга экономического положения и здоровья населения НИУ ВШЭ» за 2016 г. В этой волне мониторинга его респондентам задавался вопрос о том, к какому децилю доходного распределения они себя относят. Ответ на него мы сравниваем с фактическим децилем, в который попадает семья с данным уровнем душевого дохода. Как и многие предыдущие исследования, мы находим систематические смещения в представлениях людей: они склонны помещать себя в середину распределения и, как правило, воспринимают себя беднее, чем они есть на самом деле. Анализ показывает, что субъективное положение в распределении практически не зависит от объективной оценки динамики дохода. Наоборот, общий жизненный оптимизм и ощущение позитивных изменений в прошлом мотивируют респондентов помещать себя в более высокий доходный дециль.
\end{abstract}

Ключевые слова: распределение доходов, неравенство, восприятие.

Классификация JEL: D31, D63, I31.

DOI: $10.31737 / 2221-2264-2020-46-2-2$

\section{1. Введение}

Одна из причин особого интереса к проблеме неравенства в последнее время - предполагаемые негативные последствия его роста. Ожидания экономистов и политологов в этом отношении часто базируются на известной модели медианного избирателя МельцераРичарда (Meltzer, Richard, 1981). Она, в частности, предсказывает, что увеличение разрыва между средним и медианным доходом должно приводить к росту поддержки перераспределительной политики государства, поскольку большая часть общества ожидает для себя дополнительных благ. Также предполагается, что рост неравенства может влиять на разные формы протеста - стимулировать конфликты, митинги и забастовки и т.п. Логика модели подразумевает, что рациональные и всеведущие избиратели имеют точное представление как о масштабах неравенства, так и о своем положении в распределении по доходам. Если бы это было так, тогда существовала бы прямая зависимость между

\footnotetext{
${ }^{1}$ Данная статья подготовлена в ходе работы в рамках Программы фундаментальных исследований Национального исследовательского университета «Высшая школа экономики» (НИУ ВШЭ) с использованием средств субсидии в рамках государственной поддержки ведущих университетов Российской Федерации «5-100». Авторы признательны Ф. Слонимчику, Д. Трейсману, Р. Капелюшникову, А. Ощепкову, а также участникам семинара «Политическая экономика» факультета экономических наук НИУ ВШЭ, ХІХ Апрельской международной научной конференции по проблемам развития экономики и общества, 15-й конференции Европейской ассоциации сравнительных экономических исследований, 39-й Ежегодной конференции рабочей группы по вопросам сегментации рынка труда за полезные комментарии и предложения.
} 
уровнем неравенства в стране и поведением населения, направленным, в частности, на поддержку различных перераспределительных мер.

Однако значительное число исследований показывает, что такого рода зависимость - слабая или вообще отсутствует. В странах, где уровень неравенства выше, масштаб перераспределения, а также частота и интенсивность конфликтов не больше, чем в странах с меньшим уровнем неравенства. В литературе приводится множество объяснений, почему исследователи не фиксируют в реальности соблюдения предсказаний модели. Среди них: так называемый туннельный эффект и связанное с ним ожидание будущего роста доходов (Hirschman, 1973; Benabou, Ok, 2001; Alesina, La Ferrara, 2005; Ravallion, Lokshin, 2001), идеологические предпочтения (Alesina, Fuchs-Schondeln, 2007), представления о (не)справедливости существующего распределения (Alesina, Angeletos, 2005; Benabou, Tirole, 2006), ценностные установки, сформировавшиеся в сенситивном возрасте 18-25 лет (Alesina, Guiliano, 2011).

Еще одно объяснение расхождений между теоретическими представлениями и наблюдаемым поведением людей связано с тем, что индивиды могут просто не знать о том, каково существующее в стране распределение доходов и каково их место в нем. Даже если они считают, что знают, могут сильно ошибаться в своих оценках. Индивиды могут считать себя гораздо более бедными или богатыми (в относительном выражении), чем являются на самом деле. В результате подобных когнитивных искажений представление людей о неравенстве оказывается более важным фактором для предсказания поведения индивидов, чем реальные показатели неравенства (Niehues, 2014; Gimpelson, Treisman, 2018; Kuhn, 2011, 2015). Некоторые недавние исследования показывают связь представлений об относительном благосостоянии с удовлетворенностью жизнью (см. обзор в работе (Clark, d'Ambrosio, 2015)), доверием (Hu, 2017), участием в политических протестах (Justino, Martorano, 2016). Экспериментальные исследования также свидетельствуют о том, что люди плохо осведомлены и дополнительное информирование может менять их поведение и взгляды (Cruces, PerezTruglia, Tetaz, 2013; Kuziemko, Norton, Saez, Stantcheva, 2015; Karadja, Mollerstrom, Seim, 2017; Bublitz, 2017).

Хотя тезис об искаженном восприятии разных аспектов неравенства сегодня становится в литературе общепризнанным фактом (см. обзор соответствующей литературы в п. 2.2), причины возникновения разрыва между субъективными и объективными показателями неравенства и то, как проявление этого тезиса варьирует между странами и внутри стран, остается неизученным.

В этой работе мы анализируем формирование субъективных представлений людей о той экономической реальности, в которой они существуют. Первый вопрос, который ставится в работе, касается того, как люди видят свое место в распределении доходов и как это восприя- 
тие отличается от зафиксированного с помощью объективных данных. Второй вопрос, обсуждаемый в статье, связан с объяснением этих смещений. Если первый вопрос часто поднимался в литературе и ранее, то на второй обращали гораздо меньше внимания. Здесь мы особое внимание уделяем прошлому опыту социальной мобильности, который есть у индивидов, и уровню их жизненного оптимизма.

В поисках ответов мы используем «Российский мониторинг экономического положения и здоровья населения НИУ ВШЭ» (далее РМЭЗ). В волне этого обследования за 2016 г. респондентам задавался вопрос о том, в каком дециле распределения доходов окажутся члены их домохозяйства, если все население страны ранжировать от самых бедных до самых богатых. Ответ на него мы сравниваем с фактическим децилем, в который попадает семья с данным уровнем душевого дохода. Как и многие предыдущие исследования, мы находим систематические смещения в представлениях людей: как правило, они воспринимают себя беднее, чем они есть на самом деле. РМЭЗ содержит большой набор социально-демографических и экономических характеристик индивидов, которые используются при анализе детерминант отклонения субъективного дециля от объективного.

Работа состоит из семи разделов: в разд. 2 приведен обзор литературы по данному вопросу; в разд. 3 будут представлены данные и определены основные переменные; в разд. 4 приводятся расчеты несоответствий между субъективным и объективным положениями респондентов в распределении благосостояния; в разд. 5 и 6 исследуются факторы, объясняющие имеющиеся расхождения. В заключении подводятся итоги.

\section{2. Обзор литературы}

2.1. Измерение соответствия между субъективным

и объективным неравенствами

Обширная психологическая, социологическая и экономическая литература исследует то, как люди воспринимают такие различные экономические явления, как бедность, инфляция, безработица, налоговые ставки или коррупция. Оптика их восприятия, как правило, создает определенную аберрацию. Субъективное восприятие неравенства также привлекало внимание исследователей. Его измерение, однако, непростая задача, для решения которой предложено несколько методологических подходов.

Первый подход - выбор респондентами визуального образа распределения доходов, который, по их мнению, наилучшим образом соответствует ситуации в их стране (Niehues, 2014; Page, Goldstein, 2016). Затем на основе ответов респондентов реконструируются показатели неравенства, подобные коэффициенту Джини, и они сравниваются с объективными мерами (Niehues, 2014; Gimpelson, Treisman, 2018).

Другой способ определить субъективные взгляды на неравенство - попросить респондентов оценить заработную плату в ряде 
профессий или должностных позиций, например от неквалифицированного рабочего до председателя совета директоров крупной корпорации (Osberg, Smeeding, 2006; Kuhn, 2011, 2015; Osberg, Bechert, 2016). Ответы могут быть преобразованы в такие субъективные меры неравенства, как воспринимаемый разрыв в заработной плате между высоко и низкооплачиваемыми профессиями, а также субъективный коэффициент Джини.

Респондентов также можно напрямую спросить о разных характеристиках распределения доходов. Например, можно задать вопрос о доле богатства (дохода), которая приходится на каждый квантиль распределения, как это сделано в работе (Norton, Ariely, 2011); или о среднем богатстве или доходах домохозяйств в каждом квантиле, как в работе (Eriksson, Simpson, 2012); или о граничных значениях квантилей по доходам (Chambers, Swan, Heesacker, 2014); или о доле населения, которая находится в определенных границах доходов (Chambers et al., 2014). Эти субъективные меры неравенства могут сравниваться с объективными данными, но только - на уровне страны (или региона).

Наконец, чтобы восстановить воспринимаемое распределение доходов, можно попросить респондентов оценить, в каком доходном дециле они находятся. Поскольку каждый дециль по определению содержит $10 \%$ населения, то сумма отклонений от этой величины является потенциальной мерой искажений в восприятии неравенства (Gimpelson, Treisman, 2018; Choi, 2019). Субъективное местоположение в распределении можно сравнить с фактическим, которое оценивается с помощью объективных данных о доходах (если такая информация доступна). Другой вариант того же подхода - спросить респондентов, какой процент домашних хозяйств (или индивидов) в их стране имеет доход ниже (или выше), чем они. Ответы на этот вопрос могут быть преобразованы затем в воспринимаемое распределение доходов (этот прием применяется в работах (Cruses et al., 2013; Fernández-Albertos, Kuo, 2018; Bublitz, 2017)).

В литературе пока нет консенсуса относительно того, как можно наилучшим образом измерить субъективное отношение населения к неравенству. Здесь показателен пример США. В работе (Norton, Ariely, 2011) авторы показывают, что в США респонденты систематически недооценивают неравенство, когда их спрашивают о доле богатства, принадлежащего каждой квинтильной группе. Респонденты в среднем отвечали, что самому богатому квинтилю принадлежит $56 \%$ богатства, тогда как на самом деле это доля составляет $84 \%$. Однако когда К. Эрикссон и Б. Симпсон (Eriksson, Simpson, 2012) переформулировали вопрос, спросив о среднем богатстве домашних хозяйств в каждой квинтильной группе, оказалось, что респонденты существенно переоценивают соотношение благосостояния беднейших и богатейших американцев. В работе (Chambers et al., 2014) также обнаруживается, что американцы склонны переоценивать разрыв между 
богатством 20\% беднейшего и $20 \%$ богатейшего населения. Однако Л. Пейдж и Д.Г. Голдштейн (Page, Goldstein, 2016) показывают, что респонденты в США переоценивают средние доходы и недооценивают степень неравенства доходов домашних хозяйств в своей стране.

Однако же представление о том, что восприятие распределения доходов серьезно отличается от реальности, признается большинством авторов. В работе (Gimpelson, Treisman, 2018) авторы приводят многочисленные эмпирические свидетельства «тройного заблуждения»: индивиды неправильно представляют: 1) как выглядит распределение доходов в их странах, 2) в какой части распределения находятся они сами, 3) как неравенство изменяется во времени. Ряд межстрановых и внутристрановых опросов показывают, что большинство граждан склонны причислять себя к группе со средним доходом, хотя на самом деле они намного богаче или беднее.

Гипотеза 1. Большинство индивидов ошибочно определяет свое место в распределении доходов. Они склонны позиционировать себя ближе к середине, независимо от того, к какой части распределения они фактически принадлежат.

Эту гипотезу мы проверяем, сопоставляя субъективные оценки положения в распределении с объективными, т.е. полученными на основе статистических данных.

\section{3. Объяснения расхождений между субъективным и объективным неравенством}

Следуя работе (Gimpelson, Treisman, 2018), мы можем выдвинуть несколько потенциальных объяснений расхождений между субъективными и объективными мерами неравенства.

Первая гипотеза связывает восприятие неравенства с референтной группой или с той непосредственной социальной средой, в которой живут люди. Индивиды формируют свое восприятие, сравнивая себя с другими, - с близкими и хорошо известными им людьми друзьями, родственниками, соседями. В (Knell, Stix, 2017) авторы отмечают, что при восприятии распределения доходов могут возникнуть два типа смещений. Либо люди воспринимают только ограниченную часть распределения доходов вокруг своей собственной позиции, либо рассматривают все распределение, но придают больший вес доходам, близким к их собственной позиции. Эти гипотезы подтверждаются расчетами авторов на данных «Международной программы социальных исследований» (сокращенно ISSP) 2009 г. В (Hadavand, 2018) показано, что разрыв между субъективным восприятием и объективным местом в распределении доходов будет меньше, если объективное распределение будет скорректировано в соответствии с референтной группой респондентов. Однако (Bublitz, 2017) не находит подтверждения гипотезе о референтной группе: поляризация социальных контактов респондента не влияет на воспринимаемое место в распределении 
доходов. В ряде исследований проверяется влияние характеристик населенного пункта респондента на смещение восприятия при предположении, что место жительства формирует естественную референтную группу. Однако такая связь существует не всегда (см., например, (Page, Goldstein, 2016)).

В работе (Cruces et al., 2013) авторы обсуждают, что референтная группа, на распределение доходов в которой ориентируются респонденты, формируется эндогенно под влиянием множества факторов, одним из которых является доступ к информации. Так, например, более высокий уровень образования может уменьшать искажения в восприятии, поскольку обеспечивает лучший доступ к информации и улучшает аналитические навыки. Однако индивиды с более высоким уровнем образования обычно ориентируются на более высокодоходную референтную группу, что вносит свои искажения.

Другое потенциально важное объяснение искажений относится к идеологическим убеждениям респондентов. Респонденты с левыми взглядами могут переоценивать неравенство (прежде всего в верхней части распределения), тем самым ставя себя на более низкие позиции, чем они фактически занимают. Приверженцы более либеральных взглядов меньше беспокоятся о неравенстве в целом и с большей вероятностью отождествляют себя (и окружающих) со средним классом (Gimpelson, Treisman, 2018).

Одна из идей заключается в том, что прошлый опыт или ожидание социальной мобильности влияют на текущий субъективный статус. Восходящая мобильность повышает текущую самооценку статуса, а ожидание или опыт нисходящей мобильности его снижает. Опыт такой мобильности посылает сигнал, влияющий на поведение. В литературе это называется «туннельным эффектом», в соответствии с формулировкой А. Хиршмана, который использовал образ «застрявших в туннеле» и ожидающих обнадеживающих сигналов о начале движения (Hirschman, 1973).

Субъективное восприятие своего места на шкале распределения зависит от наличия возможностей изменить свое положение: восходящая мобильность в виде движения к более высоким децилям распределения отчасти примиряет с неравенством и ведет к тому, что испытавшие (или ожидающие) ее индивиды ставят себя выше. Стоит также отметить, что люди в разной степени подвержены влиянию позитивных и негативных сигналов. Восприятие жизненных событий зависит от личностных характеристик индивидов, в частности от того, насколько оптимистично они оценивают свою жизнь и чувствуют ли себя счастливыми. Так, более счастливые люди интенсивнее реагируют на позитивные события или информацию и легче переносят неприятный опыт (Lyubomirsky, Tucker, 1998; Lyubomirsky, Ross, 1997).

Следуя за понятием А. Хиршмана «туннельный эффект» и выводами, сделанными в (Ravallion, Lokshin, 2002), сформулируем вторую 
гипотезу, предполагающую сигнал позитивных ожиданий, который может иметь дополнительный психологический эффект:

Гипотеза 2. Индивиды, находящиеся на траектории изменения дохода, будут чувствовать себя более или менее обеспеченными (относительно объективного дохода) в зависимости от знака изменения дохода. Это означает, что для тех, кто испытал восходящую мобильность доходов, в случае переоценки своего места в распределении разрыв будет больше, а в случае недооценки - меньше.

\section{4. Данные и методология}

Мы сравниваем два показателя. Первый - мы называем его объективным - определяет местоположение респондентов в фактическом (объективном) распределении благосостояния. Второй - субъективный - основан на самооценке респондентами того доходного дециля, к которому они принадлежат. Разница между их значениями (а они имеют идентичные шкалы) будет отражать то, насколько верно респондент оценивает свое место в распределении доходов в стране.

Для измерения обоих показателей и объяснения разрыва между ними нам нужны микроданные, которые, помимо их самих, содержали бы широкий набор характеристик респондентов и их домохозяйств. Такие данные предоставляет РМЭЗ. Это лонгитюдное исследование, каждая волна которого репрезентативна на уровне страны, а также для сельского и городского населения. Репрезентативная выборка охватывает 10 тысяч взрослых, которые живут почти в 5 тысячах домохозяйств. 25-я волна обследования, проведенная в октябре 2016 г., предоставляет всю необходимую для нашего анализа информацию.

Представим основные переменные, использованные для сопоставления объективного и субъективного места респондентов в распределении доходов.

Вопрос РМЭЗ о воспринимаемом дециле формулируется следующим образом: «Представьте себе, пожалуйста, лестницу из десяти ступеней, где на каждой ступени стоят по $10 \%$ всего населения нашей страны. На нижней, первой ступени, находятся $10 \%$ самых бедных семей, а на высшей, десятой $-10 \%$ самых богатых семей. На какой из десяти ступеней находится сегодня ваша семья?» Отвечая, респондент должен приписать себя к конкретному децилю, согласно собственному представлению о распределении доходов в обществе. Таким образом, этот вопрос направлен на то, чтобы измерить благосостояние респондента именно относительно других жителей страны, а не относительно абстрактных представлений о бедности и богатстве.

Объективное положение индивида в распределении благосостояния можно измерить с помощью таких различных показателей, как доход, потребление или богатство. Мы используем альтернативные переменные, но наш предпочитаемый показатель - денежный доход на одного члена домохозяйства. Он рассчитывается на основе 
информации из вопроса: «Скажите, пожалуйста, каким был денежный доход всей вашей семьи в течение последних 30 дней? Включите сюда все денежные поступления всех членов семьи: заработную плату, пенсии, стипендии, любые другие денежные поступления, в том числе и в валюте, но валюту переведите в рубли».

Общий денежный доход домохозяйства мы преобразуем в душевой доход, используя шкалу эквивалентности ОЭСР, чтобы учесть размер и состав домохозяйства. Также доходы корректируются с учетом стоимости жизни в регионе по данным Росстата. Респондентам присваивается объективный дециль в соответствии с их местом в распределении подушевого дохода в выборке. Такой способ ранее применялся в работах (Jäntti, Kanbur, Nyyssölä, Pirttilä, 2014; Denisova, 2007; Stillman, 2001; Ravallion, Lokshin, 1999).

В качестве основных зависимых переменных мы используем два варианта разности, или разрыва, между субъективным (воспринимаемым) и объективным (оцениваемым на основе обследований) децилями положения на шкале распределения доходов. Первый разрыв с учетом знака $\left(g a p=X_{m p}-X_{a c t}\right)$; он показывает ошибку восприятия, учитывающую степень либо недооценки (знак «-»), либо переоценки (знак «+»). Второй - абсолютный разрыв, представляющий эту разность как меру абсолютной ошибки восприятия без учета знака $\left(g_{a p}=\left|X_{m p}-X_{a c t}\right|\right)$. Кроме того, в качестве зависимой переменной используется также переменная с тремя категориями: индивид недооценивает свое положение (отрицательный разрыв), индивид правильно оценивает свое положение (разрыв равен нулю) и индивид переоценивает свое положение (положительный разрыв).

При сравнении субъективного и объективного показателей необходимо учитывать потенциальные ошибки измерения, связанные с обоими показателями. Мы считаем маловероятным, что респонденты будут сознательно искажать ответы на субъективный вопрос. Однако данные о фактическом доходе являются во многих отношениях чувствительной информацией, которую респонденты часто скрывают или искажают. По этой причине мы проверяем основной результат, применяя альтернативные показатели, среди которых доход домохозяйства, полученный суммированием отдельных категорий, потребительские расходы домохозяйства ${ }^{2}$ и индекс активов ${ }^{3}$. Использовать разные меры имеет смысл также и потому, что мы не знаем, какое именно измерение благосостояния имеют в виду респонденты, когда отвечают на этот вопрос. Они при этом могут думать как о доходе, так и о богатстве или потреблении. Дополнительное смещение в результатах может возникать из-за возможной нерепрезентативности выборки. Мы проводим проверку результата, предполагая, что из опроса выпадают верхние $10 \%$ распределения доходов.

\footnotetext{
2 Потребительские расходы включают расходы на питание и непродовольственные товары, исключая расходы на ремонт жилья или строительные работы. Потребление товаров длительного пользования и аренда жилья не включаются из-за ограниченности данных.

${ }^{3}$ Индекс строится методом главных компонент на основе информации о владении товарами длительного пользования и качестве жилья, методология построения индекса следует работе (Wall, Johnston, 2008).
} 
В качестве объясняющих переменных используется ряд социально-демографических и экономических характеристик индивидов и их домохозяйств, доступных в РМЭЗ (табл. 1). Личные характеристики респондентов включают следующие переменные: пол, возраст, состояние в браке, занятость на рынке труда, уровень образования и самооценка здоровья. Среди характеристик домохозяйств - его размер и состав, а также тип населенного пункта, в котором домохозяйство проживает. Перечисленные факторы могут отражать психологические особенности индивидов, влияющие на самооценку их положения, особенности их референтной группы, а также учитывать материальные потребности домохозяйств.

Таблица 1

Характеристики респондентов

\begin{tabular}{|c|c|c|}
\hline Характеристика & Среднее & Стандартное отклонение \\
\hline \multicolumn{3}{|c|}{ Личные характеристики } \\
\hline Мужчины, \% & 40,9 & 49,2 \\
\hline Возраст & 49,0 & 17,9 \\
\hline Состоит в браке, \% & 62,1 & 48,5 \\
\hline \multicolumn{3}{|l|}{ Уровень образования: } \\
\hline общее среднее и ниже, \% & 32,9 & 47,0 \\
\hline среднее специальное, \% & 39,7 & 48,9 \\
\hline высшее, \% & 27,4 & 44,6 \\
\hline Имеет работу, \% & 56,6 & 49,6 \\
\hline \multicolumn{3}{|c|}{ Субъективное состояние здоровья } \\
\hline хорошее, очень хорошее, \% & 34,5 & 47,5 \\
\hline нормальное, \% & 51,7 & 50,0 \\
\hline плохое, очень плохое, \% & 13,8 & 34,5 \\
\hline \multicolumn{3}{|c|}{ Характеристики домохозяйства } \\
\hline Число членов домохозяйства & 3,3 & 1,8 \\
\hline Доля детей, \% & 10,6 & 16,6 \\
\hline Доля пенсионеров, \% & 38,5 & 38,8 \\
\hline \multicolumn{3}{|l|}{ Тип населенного пункта: } \\
\hline Москва, Санкт-Петербург, \% & 11,5 & 32,0 \\
\hline столица субъекта РФ, \% & 30,6 & 46,1 \\
\hline другой город, \% & 25,6 & 43,6 \\
\hline поселок городского типа, \% & 6,5 & 24,7 \\
\hline сельское поселение, \% & 25,8 & 43,7 \\
\hline
\end{tabular}

Примечание. Выборка ответивших на вопрос о субъективном дециле, число опрошенных - 9651 . 


\section{5. Субъективное расположение в распределении доходов: описательная статистика}

Распределение респондентов по объективным децилям - по построению - является равномерным (если верно предположение, что наша выборка корректно представляет население). Каждый индивид относится только к одному децилю, содержащему $10 \%$ выборки. Ответы на субъективный вопрос с десятью ступенями-децилями представлены на рис. 1. Большинство респондентов ставят себя чуть ниже середины распределения: более $70 \%$ находятся в децилях с третьего по пятый, включительно. Они в значительной степени недопредставлены на первой ступени (4,7\% респондентов вместо $10 \%)$ и на ступенях с шестой по десятую (суммарно $10 \%$ вместо $50 \%$ ). В результате вместо равномерного распределения с десятью процентами в каждом дециле мы имеем квазинормальное - с модой в третьем дециле. Таким образом, данные РМЭЗ подтверждают, что люди, как правило, неверно оценивают свое местоположение в распределении доходов. Большинство респондентов склонны недооценивать свое положение, но многие его переоценивают. Эта картина близка к той, что представлена в работе (Gimpelson, Treisman, 2018).

Далее мы сравниваем субъективное положение респондента с его действительным местом в распределении доходов. Ошибки восприятия очень распространены, и оба направления смещения - отрицательное, когда недооценивается своя истинная позиция, и положительное, когда переоценивается, - имеют место (рис. 2). Две трети респондентов (69\%) недооценивают дециль, к которому они принадлежат, и только один из десяти $(11 \%)$ оценивает его правильно. Более того, каждый пятый (22\%) ошибается по менышей мере на $5(!)$ децилей. Значительная часть выборки (20\%) оценивает свое место выше, чем оно есть на самом деле. Средняя ошибка в выборке составляет 2 дециля (стандартное отклонение 2,9 ), а средний размер ее абсолютного значения составляет 2,9 (стандартное отклонение 2,0 ).

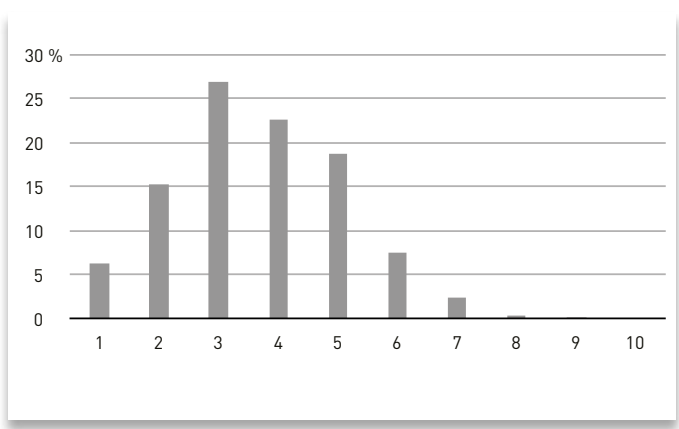

Puc. 1

Субъективное положение в распределении благосостояния, РМЭЗ, 2016 г.

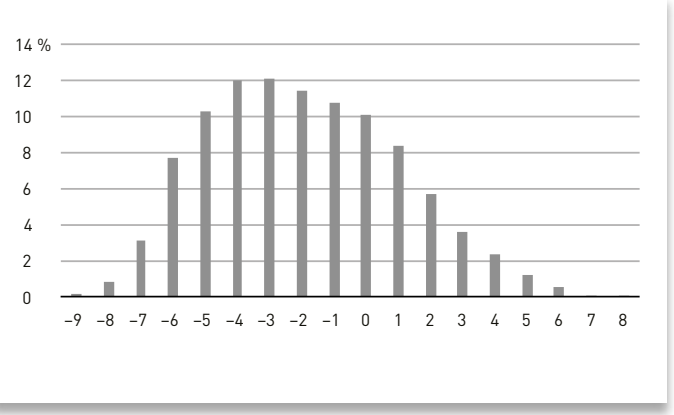

Puc. 2

Разница между субъективным и объективным дечилем, РМЭЗ, 2016 г. 
Для измерения степени отклонения в восприятии респондентами своего положения мы оцениваем индекс ошибочного восприятия $(\operatorname{Imp})$ :

$$
\operatorname{Imp}=\left(\sum_{j}\left|X m p_{j}-X a c t_{j}\right|\right) / 10,
$$

где $X m p_{j}$ и $X a c t_{j}-$ доли выборки, приходящиеся соответственно на субъективный и объективный децили $j$ (по построению $-10 \%$ ). В нашей выборке индекс Imp равен 8,8, т.е. в среднем в каждом субъективном дециле $(10 \%)$ не хватает или содержится лишних почти $9 \%$ выборки.

В табл. 2 показаны величины разрыва (средняя разница между субъективным и объективным децилями) для респондентов, относящихся ко всем объективным децилям. Те, кто относится к первому и второму объективным децилям, в среднем переоценивают свое положение в распределении благосостояния, тогда как те, кто находится в объективных децилях с пятого по десятый, склонны недооценивать свое положение (табл. 2, столбец 1). Те, кто находится в третьем и четвертом децилях, дают наиболее точные оценки своего положения в распределении доходов. Абсолютный размер ошибки всегда статистически отличается от нуля. Более того, поскольку респонденты в децилях с шестого по десятый почти никогда не переоценивают свою позицию, абсолютная величина разрыва совпадает со средним значением (см. табл. 2, столбец 3).

Итак, мы наблюдаем существенные различия между воспринимаемыми и фактическими позициями в распределении доходов. Большинство недооценивает свое фактическое положение, измеренное доходом на одного члена домохозяйства. Респонденты склонны размещать себя чуть ниже центра - в третьем и четвертом децилях.

Таблица 2

Разница между воспринимаемым и объективным децилями по подушевому доходу домохозяйства

\begin{tabular}{|c|c|c|c|c|}
\hline \multirow{2}{*}{$\begin{array}{c}\text { Объективный } \\
\text { дециль }\end{array}$} & $\begin{array}{c}\text { Разница между объективным и субъ- } \\
\text { ективным децилями }\end{array}$ & \multicolumn{2}{|c|}{$\begin{array}{c}\text { Абсолютная разница между объек- } \\
\text { тивным и субъективным децилями }\end{array}$} \\
\cline { 2 - 5 } & Среднее & $\begin{array}{c}\text { Стандартное } \\
\text { отклонение }\end{array}$ & Среднее & $\begin{array}{c}\text { Стандартное } \\
\text { отклонение }\end{array}$ \\
\hline \hline 1 & 2,3 & 1,5 & 2,3 & 1,5 \\
\hline 2 & 1,1 & 1,5 & 1,4 & 1,2 \\
\hline 3 & 0,3 & 1,4 & 1,1 & 0,9 \\
\hline 4 & $-0,6$ & 1,3 & 1,2 & 0,9 \\
\hline 5 & $-1,5$ & 1,3 & 1,6 & 1,1 \\
\hline 6 & $-2,4$ & 1,3 & 2,5 & 1,2 \\
\hline 7 & $-3,5$ & 1,3 & 3,5 & 1,3 \\
\hline 8 & $-4,1$ & 1,3 & 4,1 & 1,3 \\
\hline 9 & $-4,9$ & 1,3 & 4,9 & 1,3 \\
\hline 10 & $-5,6$ & 1,3 & 5,6 & 1,3 \\
\hline
\end{tabular}


5.1. Проверка результатов: альтернативное измерение

благосостояния

Как упоминалось выше, существует проблема выбора показателя, который бы соответствовал представлениям о бедности и богатстве респондентов, отвечающих на субъективный вопрос. Помимо денежных доходов, люди могут думать о потреблении или накопленном имуществе. В табл. 3 показаны средние величины разрывов между субъективной и объективной оценками положения в распределении при использовании альтернативных объективных показателей. Как мы видим, использование альтернативных показателей благосостояния лишь незначительно меняет оценку разрыва. Средний размер разрыва, когда учитывается знак смещения, колеблется около - 1,9 дециля. Если знак ошибки не учитывается, то в среднем она составляет 2,8-2,9 дециля.

Наблюдаемые разрывы могут быть вызваны ошибками измерения дохода. Если в качестве альтернативного показателя мы используем сумму доходов по отдельным статьям, средний разрыв несколько уменьшается, а в абсолютном выражении - увеличивается, однако отличия статистически незначимы (см. табл. 3, строка 2). Изменения связаны с добавлением наблюдений в левом хвосте распределения доходов, где люди склонны переоценивать свое относительное положение.

Использование потребительских расходов (как общих, так и текущих) в качестве альтернативной меры благосостояния также существенно не меняет базового результата. Средний абсолютный разрыв сохраняется, а средний разрыв несколько снижается, в том числе и из-за того, что респонденты из левой части распределения благосостояния более склонны сообщать о потреблении, чем о доходах (см. табл. 3, строки 3-4).

Таблица 3

Альтернативные оценки разрыва между субъективной и объективной оценками

\begin{tabular}{|c|c|c|c|c|c|}
\hline Объективный показатель благосостояния & 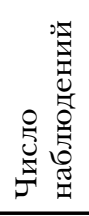 & 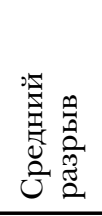 & 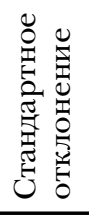 & 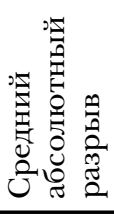 & 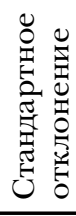 \\
\hline Вопрос о доходах (базовый результат) & 9104 & $-2,03$ & 2,84 & 2,87 & 1,98 \\
\hline Доходы - сумма по отдельным статьям & 9416 & $-1,99$ & 2,95 & 2,95 & 1,99 \\
\hline Общие потребительские расходы & 9634 & $-1,84$ & 3,00 & 2,86 & 2,05 \\
\hline Текущие потребительские расходы" & 9630 & $-1,86$ & 3,02 & 2,89 & 2,06 \\
\hline Индекс активов & 9674 & $-1,70$ & 2,86 & 2,67 & 1,98 \\
\hline Вопрос о доходах, добавлены 10\% справа & 9104 & $-1,57$ & 2,62 & 2,51 & 1,74 \\
\hline
\end{tabular}

Примечание. Символом «"» отмечены общие расходы без расходов на ремонт и товары длительного пользования. 
Еще одна альтернативная мера - индекс активов, который отражает более долгосрочные тенденции в благосостоянии домохозяйств. Индекс активов имеет самое близкое соответствие с субъективным положением среди всех показателей, используемых в нашем анализе. Хотя разница между оценками невелика, она статистически значима: средний абсолютный разрыв составляет 2,67 при использовании индекса активов, тогда как при базовом варианте расчетов $-2,87$.

Потенциальное смещение в наших результатах также может быть вызвано смещением выборки РМЭЗ. Как известно, любые опросы домохозяйств плохо улавливают респондентов в правом хвосте распределения доходов. Даже если респонденты РМЭЗ, отвечающие на вопрос о субъективном месте в распределении благосостояния, верно оценивают свое место в действительно существующем, правильном, распределении, наши расчеты могут быть искажены из-за несовершенства выборки. Для оценки робастности результатов мы прикрепляем к распределению РМЭЗ справа 10\% распределения (см. табл. 3, строка 6), следуя предположению авторов работы (Novokmet et al., 2018) о том, что выборка РМЭЗ покрывает нижние $90 \%$ распределения доходов. Если допустить, что выборка РМЭЗ полностью упускает верхний дециль распределения доходов, то мы примерно на четверть переоцениваем размер разрыва. Тем не менее ошибки все равно остаются весьма существенными.

\section{6. Как объяснить разрыв (между объективным положением и его субъективной оценкой)}

Как показывает наш дескриптивный анализ, респонденты РМЭЗ в среднем ошибаются на 2,8 дециля (в абсолютном выражении) по сравнению со своим объективным положением в распределении доходов. В верхних децилях распределения разрыв значительно больше. Но какие факторы влияют на размер и знак разрыва?

Табл. 4 показывает средний размер разрыва для различных социально-демографических групп. Он - больше для тех, кто находится в браке, лучше образован, занят и имеет хорошее здоровье (это касается абсолютных ошибок). Что касается места проживания, наибольший разрыв оказывается у жителей региональных столиц. Однако описанные различия между группами статистически незначимы.

В качестве следующего шага в изучении факторов, которые могут повлиять на степень искаженности восприятия, мы оцениваем следующее регрессионное уравнение

$$
G A P_{i}=\beta \ln \left(y_{i}\right)+\gamma X_{i}+\varepsilon_{i},
$$

где $G A P_{i}$ - разница между субъективным и объективным децилями распределения доходов, $X_{i}$ - характеристики индивида $i, \ln (\mathrm{y})-$ логарифм подушевого дохода домохозяйства индивида $i, \varepsilon_{i}$ - случайная ошибка. 
Таблица 4

Различие между субъективным и объективным децилями по социально-демографическим группам

\begin{tabular}{|c|c|c|c|c|}
\hline $\begin{array}{c}\text { Индивидуальная } \\
\text { характеристика }\end{array}$ & $\begin{array}{c}\text { Средний } \\
\text { разрыв }\end{array}$ & $\begin{array}{c}\text { Стандартная } \\
\text { ошибка }\end{array}$ & $\begin{array}{c}\text { Средний абсолют- } \\
\text { ный разрыв }\end{array}$ & $\begin{array}{c}\text { Стандартная } \\
\text { ошибка }\end{array}$ \\
\hline Женщины & $-1,9$ & 0,04 & 2,8 & 0,03 \\
\hline Мужчины & $-1,9$ & 0,05 & 2,8 & 0,03 \\
\hline Состоит в браке & $-1,7$ & 0,05 & 2,7 & 0,03 \\
\hline Не состоит в браке & $-2,0$ & 0,04 & 2,9 & 0,03 \\
\hline \multicolumn{5}{|c|}{ Уровень образования } \\
\hline Ниже общего среднего & $-1,1$ & 0,08 & 2,3 & 0,05 \\
\hline Общее среднее & $-1,4$ & 0,07 & 2,7 & 0,04 \\
\hline $\begin{array}{l}\text { Начальное } \\
\text { профессиональное }\end{array}$ & $-1,8$ & 0,08 & 2,7 & 0,06 \\
\hline $\begin{array}{l}\text { Среднее } \\
\text { профессиональное }\end{array}$ & $-2,0$ & 0,06 & 2,9 & 0,04 \\
\hline Высшее & $-2,8$ & 0,06 & 3,3 & 0,04 \\
\hline \multicolumn{5}{|c|}{ Возраст } \\
\hline $18-30$ & $-1,8$ & 0,07 & 2,9 & 0,05 \\
\hline $31-40$ & $-1,7$ & 0,07 & 2,8 & 0,05 \\
\hline $41-50$ & $-2,0$ & 0,08 & 2,9 & 0,05 \\
\hline $51-60$ & $-2,3$ & 0,07 & 3,1 & 0,05 \\
\hline$>60$ & $-1,9$ & 0,05 & 2,6 & 0,04 \\
\hline \multicolumn{5}{|c|}{ Самооценка здоровья } \\
\hline Хорошее, очень хорошее & $-1,7$ & 0,06 & 2,9 & 0,03 \\
\hline Нормальное & $-2,0$ & 0,04 & 2,8 & 0,03 \\
\hline Плохое, очень плохое & $-2,0$ & 0,07 & 2,5 & 0,05 \\
\hline Имеет работу & $-1,3$ & 0,04 & 2,4 & 0,03 \\
\hline Не имеет работы & $-2,4$ & 0,04 & 3,2 & 0,03 \\
\hline \multicolumn{5}{|c|}{ Населенный пункт } \\
\hline Москва, Санкт-Петербург & $-2,2$ & 0,08 & 2,9 & 0,06 \\
\hline Столица региона & $-2,8$ & 0,05 & 3,2 & 0,04 \\
\hline Другой город & $-2,3$ & 0,05 & 2,9 & 0,04 \\
\hline Поселок городского типа & $-0,6$ & 0,13 & 2,8 & 0,07 \\
\hline Сельская местность & $-0,6$ & 0,06 & 2,3 & 0,04 \\
\hline
\end{tabular}

Также мы оцениваем мультиномиальную логит-регрессию, в которой зависимая переменная принимает три значения:

$$
P(\text { Bias }=c)=\exp \left(\beta_{c} \ln \left(y_{i}\right)+\gamma_{c} X_{i}\right) / \sum_{k=1}^{K}\left(\exp \left(\beta_{k} \ln \left(y_{i}\right)+\gamma_{k} X_{i}\right)\right),
$$

где Bias - характеристика разрыва между субъективным и объективным децилем; она равна - 1 , если разрыв отрицательный, 0 , если он отсут- 
ствует, +1 , если положительный; $X_{i}$ - характеристики индивида $i$; $\ln (y)$ - логарифм подушевого дохода домохозяйства индивида $i$.

Набор объясняющих переменных включает образование, возраст, пол, статус занятости, размер и состав домохозяйства, а также здоровье индивида и тип населенного пункта, в котором он проживает. Все объясняющие переменные могут влиять на разрыв через доход, а также через восприятие. При этом влияние может транслироваться по различным каналам: через различия в потребностях, особенности референтной группы, доступ к информации, психологические особенности и идеологические взгляды.

В табл. 5 представлены оценки коэффициентов из уравнений (2) и (3). Из нее следует, что размер разрыва увеличивается с ростом дохода: более богатые люди чаще недооценивают свое местоположение в распределении доходов. Однако добавление индекса активов в регрессию показывает, что при контроле дохода с ростом накопленного богатства восприятие становится более позитивным (табл. 5, столбцы $1,3,5)$. Этот результат свидетельствует о том, что один денежный доход не полностью отражает материальное благосостояние домашних хозяйств. Потребление домохозяйства также увеличивает

Таблица 5

Факторы формирования разрыва между субъективным и объективным положениями респондентов в распределении доходов

\begin{tabular}{|c|c|c|c|c|c|}
\hline \multirow{3}{*}{$\begin{array}{c}\text { Переменная, включенная } \\
\text { в регрессию }\end{array}$} & \multicolumn{3}{|c|}{ OLS } & \multicolumn{2}{|c|}{ mlogit } \\
\hline & 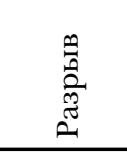 & 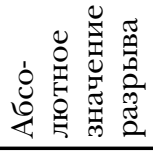 & 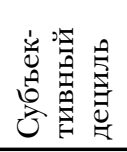 & 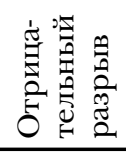 & 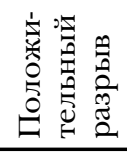 \\
\hline & (1) & $(2)$ & $(3)$ & $(4)$ & $(5)$ \\
\hline \multirow{2}{*}{$\begin{array}{l}\text { Логарифм подушевого дохода } \\
\text { домохозяйства }\end{array}$} & $-4,49^{* * * *}$ & $2,21^{* * * * *}$ & $0,51^{* * * * *}$ & $7,46^{* * * *}$ & $-2,92^{* * * *}$ \\
\hline & {$[0,131]$} & {$[0,254]$} & {$[0,073]$} & {$[0,352]$} & {$[0,339]$} \\
\hline \multirow{2}{*}{ Индекс активов } & $0,07^{*}$ & $-0,01$ & $0,11^{* * * *}$ & $-0,05$ & $0,19^{* * * *}$ \\
\hline & {$[0,032]$} & {$[0,021]$} & {$[0,030]$} & {$[0,053]$} & {$[0,041]$} \\
\hline \multirow{2}{*}{$\begin{array}{l}\text { Логарифм подушевого } \\
\text { текущего потребления } \\
\text { домохозяйства }\end{array}$} & 0,08 & $0,26^{* *}$ & 0,11 & $-0,15$ & 0,04 \\
\hline & {$[0,084]$} & {$[0,109]$} & {$[0,087]$} & {$[0,107]$} & {$[0,118]$} \\
\hline \multirow{2}{*}{ Пол: мужской } & $-0,01$ & $-0,02$ & $-0,01$ & 0,01 & $-0,08$ \\
\hline & {$[0,027]$} & {$[0,020]$} & {$[0,029]$} & {$[0,092]$} & {$[0,063]$} \\
\hline \multirow{2}{*}{ Возраст } & $-0,03^{* * * *}$ & $0,03^{\text {****** }}$ & $-0,04^{* * * *}$ & $0,07^{* * * *}$ & $-0,02$ \\
\hline & {$[0,008]$} & {$[0,006]$} & {$[0,008]$} & {$[0,019]$} & {$[0,020]$} \\
\hline \multirow{2}{*}{ Квадрат возраста } & $0,00^{* * * *}$ & $-0,00^{* * * *}$ & $0,00^{* * * * *}$ & $-0,00^{* * * *}$ & 0,00 \\
\hline & {$[0,000]$} & {$[0,000]$} & {$[0,000]$} & {$[0,000]$} & {$[0,000]$} \\
\hline \multirow{2}{*}{ Состоит в браке } & 0,04 & $-0,13^{* * * *}$ & $0,11^{*}$ & $-0,27^{* *}$ & $-0,12$ \\
\hline & {$[0,054]$} & {$[0,046]$} & {$[0,056]$} & {$[0,111]$} & {$[0,135]$} \\
\hline
\end{tabular}


Окончание таблицы 5

\begin{tabular}{|c|c|c|c|c|c|}
\hline \multirow{3}{*}{$\begin{array}{c}\text { Переменная, включенная } \\
\text { в регрессию }\end{array}$} & \multicolumn{3}{|c|}{ OLS } & \multicolumn{2}{|c|}{ mlogit } \\
\hline & 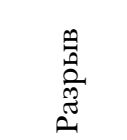 & 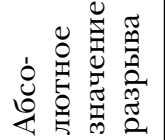 & 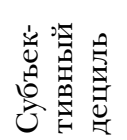 & 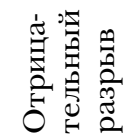 & 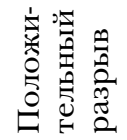 \\
\hline & $(1)$ & $(2)$ & $(3)$ & $(4)$ & $(5)$ \\
\hline \multicolumn{6}{|c|}{ Уровень образования (базовая категория - ниже общего среднего) } \\
\hline \multirow{2}{*}{ Общее среднее } & $0,17 *$ & 0,06 & 0,15 & $-0,05$ & $0,33 *$ \\
\hline & {$[0,097]$} & {$[0,075]$} & {$[0,097]$} & {$[0,181]$} & {$[0,185]$} \\
\hline \multirow{2}{*}{ Начальное профессиональное } & 0,08 & 0,03 & 0,07 & $-0,14$ & 0,18 \\
\hline & {$[0,069]$} & {$[0,071]$} & {$[0,057]$} & {$[0,170]$} & {$[0,179]$} \\
\hline \multirow{2}{*}{ Среднее профессиональное } & $0,12^{*}$ & 0,01 & $0,12^{* *}$ & $-0,28^{*}$ & 0,12 \\
\hline & {$[0,064]$} & {$[0,077]$} & {$[0,056]$} & {$[0,170]$} & {$[0,148]$} \\
\hline \multirow{2}{*}{ Высшее } & $0,22^{* * *}$ & $-0,02$ & $0,26^{* * * *}$ & $-0,35^{*}$ & 0,07 \\
\hline & {$[0,080]$} & {$[0,085]$} & {$[0,076]$} & {$[0,205]$} & {$[0,194]$} \\
\hline \multicolumn{6}{|c|}{ Здоровье: базовая категория - хорошее } \\
\hline \multirow{2}{*}{ Нормальное } & $-0,23^{* * *}$ & $-0,08$ & $-0,29^{* * * *}$ & 0,03 & $-0,48^{* * * *}$ \\
\hline & {$[0,084]$} & {$[0,064]$} & {$[0,090]$} & {$[0,167]$} & {$[0,158]$} \\
\hline \multirow{2}{*}{ Плохое } & $-0,61^{* * * *}$ & $-0,07$ & $-0,68^{\text {***** }}$ & $0,62^{* * * *}$ & $-0,84^{\text {***** }}$ \\
\hline & {$[0,123]$} & {$[0,100]$} & {$[0,127]$} & {$[0,213]$} & {$[0,231]$} \\
\hline \multirow{2}{*}{ Имеет работу } & $-0,12^{* *}$ & 0,05 & $0,12^{* * *}$ & 0,06 & $0,24^{*}$ \\
\hline & {$[0,046]$} & {$[0,052]$} & {$[0,049]$} & {$[0,120]$} & {$[0,133]$} \\
\hline \multirow{2}{*}{$\begin{array}{l}\text { Размер домохозяйства } \\
\text { (логарифм) }\end{array}$} & 0,06 & 0,09 & 0,07 & 0,16 & $0,28^{*}$ \\
\hline & {$[0,131]$} & {$[0,081]$} & {$[0,120]$} & {$[0,171]$} & {$[0,157]$} \\
\hline \multirow{2}{*}{ Доля детей в домохозяйстве } & $0,44^{*}$ & $-0,62^{* * *}$ & 0,09 & 0,34 & 0,35 \\
\hline & {$[0,241]$} & {$[0,208]$} & {$[0,218]$} & {$[0,457]$} & {$[0,393]$} \\
\hline \multirow{2}{*}{$\begin{array}{l}\text { Доля пенсионеров } \\
\text { в домохозяйстве }\end{array}$} & $-0,04$ & $-0,23^{* * *}$ & $-0,06$ & $0,55^{* *}$ & $0,41^{*}$ \\
\hline & {$[0,080]$} & {$[0,085]$} & {$[0,068]$} & {$[0,233]$} & {$[0,239]$} \\
\hline \multicolumn{6}{|c|}{ Тип поселения: базовая категория - Москва и Санкт-Петербург } \\
\hline \multirow{2}{*}{ Столица региона } & $-0,71^{* * * *}$ & $0,45^{* * * * *}$ & $-0,51^{\text {***** }}$ & $0,64^{* *}$ & $-0,37$ \\
\hline & {$[0,192]$} & {$[0,127]$} & {$[0,159]$} & {$[0,277]$} & {$[0,243]$} \\
\hline \multirow{2}{*}{ Другой город } & $-0,42^{* * * *}$ & $0,25^{* * *}$ & $-0,31^{\text {**** }}$ & $0,41^{*}$ & $-0,11$ \\
\hline & {$[0,134]$} & {$[0,097]$} & {$[0,098]$} & {$[0,226]$} & {$[0,216]$} \\
\hline \multirow{2}{*}{ Поселок городского типа } & 0,23 & $0,51^{* * *}$ & 0,29 & 0,38 & $0,66^{* * * * *}$ \\
\hline & {$[0,218]$} & {$[0,216]$} & {$[0,239]$} & {$[0,274]$} & {$[0,229]$} \\
\hline \multirow{2}{*}{ Сельское поселение } & $-0,20$ & $0,36^{\text {**** }}$ & $-0,21$ & 0,25 & $-0,00$ \\
\hline & {$[0,163]$} & {$[0,088]$} & {$[0,127]$} & {$[0,208]$} & {$[0,163]$} \\
\hline \multirow{2}{*}{ Константа } & $42,57^{* * * *}$ & $-22,18^{* * * *}$ & $-1,56^{* *}$ & $-71,64^{* * * *}$ & $28,10^{* * * *}$ \\
\hline & {$[1,024]$} & {$[1,697]$} & {$[0,589]$} & {$[3,303]$} & {$[3,306]$} \\
\hline Число наблюдений & 8688 & 8688 & 8688 & 8688 & 8688 \\
\hline$R$-квадрат & 0,719 & 0,413 & 0,185 & & \\
\hline
\end{tabular}

Примечание.В таблицесимволами «*** »обозначенызначения,длякоторых $p<0,01$, « "* $-p<0,05$, « " $p<0,1$; федеральные округа контролируются, стандартные ошибки кластеризованы по переменной $p s u$ (первичная ячейка отбора). 
размер разрыва при контроле дохода, однако коэффициенты статистически незначимы (кроме абсолютного разрыва).

А как разрыв варьирует по основным социально-демографическим характеристикам? С возрастом и ухудшением здоровья респонденты сильнее недооценивают свою относительную позицию по доходам (табл. 5, столбцы 1 и 3). Этот пессимизм может отражать не только когнитивные искажения, но и рост потребностей, связанных с поддержанием здоровья. Увеличение расходов на медицинские нужды снижает уровень жизни человека (даже при том же уровне общих расходов) и таким образом снижает самооценку благосостояния. Больше детей в семье делает восприятие более позитивным и менее смещенным в целом. Такой оптимистичный настрой может быть вызван позитивным психологическим восприятием, а также әффектом экономии на масштабе в более крупных домохозяйствах, который мы не смогли полностью учесть стандартной шкалой эквивалентности. Статистически значимых гендерных различий в восприятии нет. Наличие супруга/ супруги связано с более позитивной самооценкой благосостояния. Наконец, более высокая доля пенсионеров в домохозяйстве снижает абсолютный разрыв.

Более образованные респонденты менее склонны недооценивать свою позицию в распределении доходов; возможно, из-за того, что они более позитивно оценивают свои перспективы в будущем. При этом абсолютный разрыв для более образованных респондентов не сокращается: «больше образования» не превращается в «более точную информацию». Факт занятости увеличивает отрицательный разрыв, что несколько странно, поскольку занятые имеют более высокую субъективную оценку своего положения и более вероятно ее переоценивают.

Также интересно рассмотреть влияние места жительства. У жителей региональных центров максимальный отрицательный разрыв между субъективным и объективным децилями. За региональными центрами следуют остальные города, жители которых имеют несколько более позитивное восприятие своего положения. У жителей столиц еще более позитивные представления, которые находятся на том же уровне, что и у жителей поселков городского типа. Этот результат может говорить о том, что положение в местном распределении дохода влияет на восприятие респондентов, поскольку мы сравниваем людей с одинаковым уровнем дохода, но проживающих в разных местах. Столицы выделяются, по-видимому, по причине того, что, несмотря на более высокое неравенство, сам факт жизни в столице увеличивает самооценку социально-экономического статуса респондентов. В столицах предоставляются более качественные социальные услуги, а также сама культурная и социальная жизнь более разнообразна, что делает их восприятие более позитивным. Что касается абсолютного разрыва, то он самый маленький в столицах и самый большой - в малых населенных пунктах. 


\section{7. Динамика доходов и поведение разрыва}

Хотя текущие (субъективный и объективный) децили мы (к сожалению) видим только в один момент времени - на момент обследования, субъективные и объективные изменения в благосостоянии индивидов, произошедшие в недавнем прошлом, нам известны. Влияет ли наблюдаемая динамика доходов на величину и знак разрыва? Теоретически индивидуальное восприятие текущего положения не должно зависеть от того, находится ли индивид на восходящей или нисходящей траектории доходов. Однако связанный с траекторией оптимизм или пессимизм может модифицировать восприятие текущего положения, что может интерпретироваться как проявление туннельного эффекта.

Туннельный эффект может усиливаться психологическими особенностями индивидов. Например, индивиды, отличающиеся оптимистическим восприятием жизни, будут сильнее реагировать на такого рода позитивные сигналы, а пессимисты, наоборот, острее воспринимают негативные. Само по себе текущее психологическое состояние индивидов также может повлиять на восприятие своего места в распределении благосостояния. Такие различные эмоции, как чувство обделенности, чувство радости, уверенность в себе, желание быть, «как все», или отличаться от других, потенциально влияют на самооценки положения.

Результаты эконометрического анализа связи между разрывом в децилях и показателями мобильности по шкале доходов представлены в табл. 6-84. В табл. 6 приведены коэффициенты для переменных субъективного изменения материального положения за последние 12 месяцев ${ }^{5}$, изменения доходов за 12 месяцев (в \%) и изменения доходов за период 2013-2016 гг. (в \% ). В табл. 7 содержатся оценки для тех же переменных, но с добавлением переменной «счастье» ${ }^{6}$ и введении интеракций между «счастьем» и переменными изменений в доходах. Она отвечает на вопрос о том, как психологическое состояние может повлиять на оценки благосостояния. И, наконец, в табл. 8 представлен результат для показателей не абсолютного, а относительного роста доходов как в объективном, так и в субъективном измерениях. Под относительным ростом доходов понимается изменение доходного дециля, к которому относятся респонденты. Вертикальные столбцы соответствуют различным спецификациям оцениваемых уравнений, различающимся как набором независимых переменных, так и используемым методом оценивания (МНК и МНЛогит). Во всех случаях мы контролируем большой набор индивидуальных характеристик (пол, возраст, образование, семейное положение, наличие детей, место жительства), коэффициенты для которых не приводим из соображений экономии места.

\footnotetext{
${ }^{4}$ Описание использованных переменных см. в Приложении.

${ }^{5}$ Ответ на вопрос анкеты: «Скажите, пожалуйста, как изменилось материальное положение Вашей семьи за последние 12 месяцев?» с пятью вариантами ответа от «значительно улучшилось» до «значительно ухудшилось»

${ }^{6}$ Ответ на вопрос анкеты: «Скажите, пожалуйста, Вы счастливы?» с пятью вариантами ответа от «совсем несчастливы» до «очень счастливы».
} 


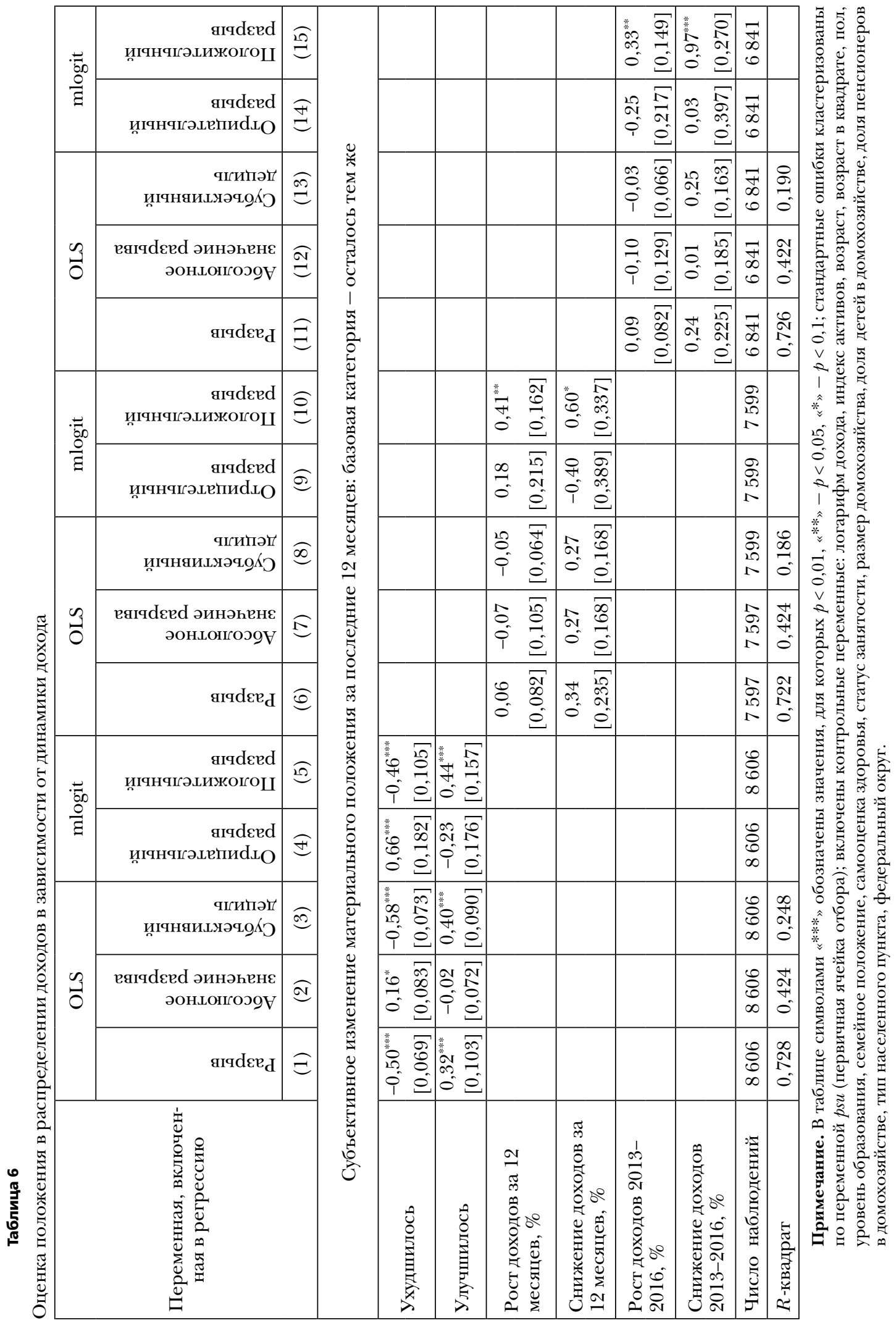




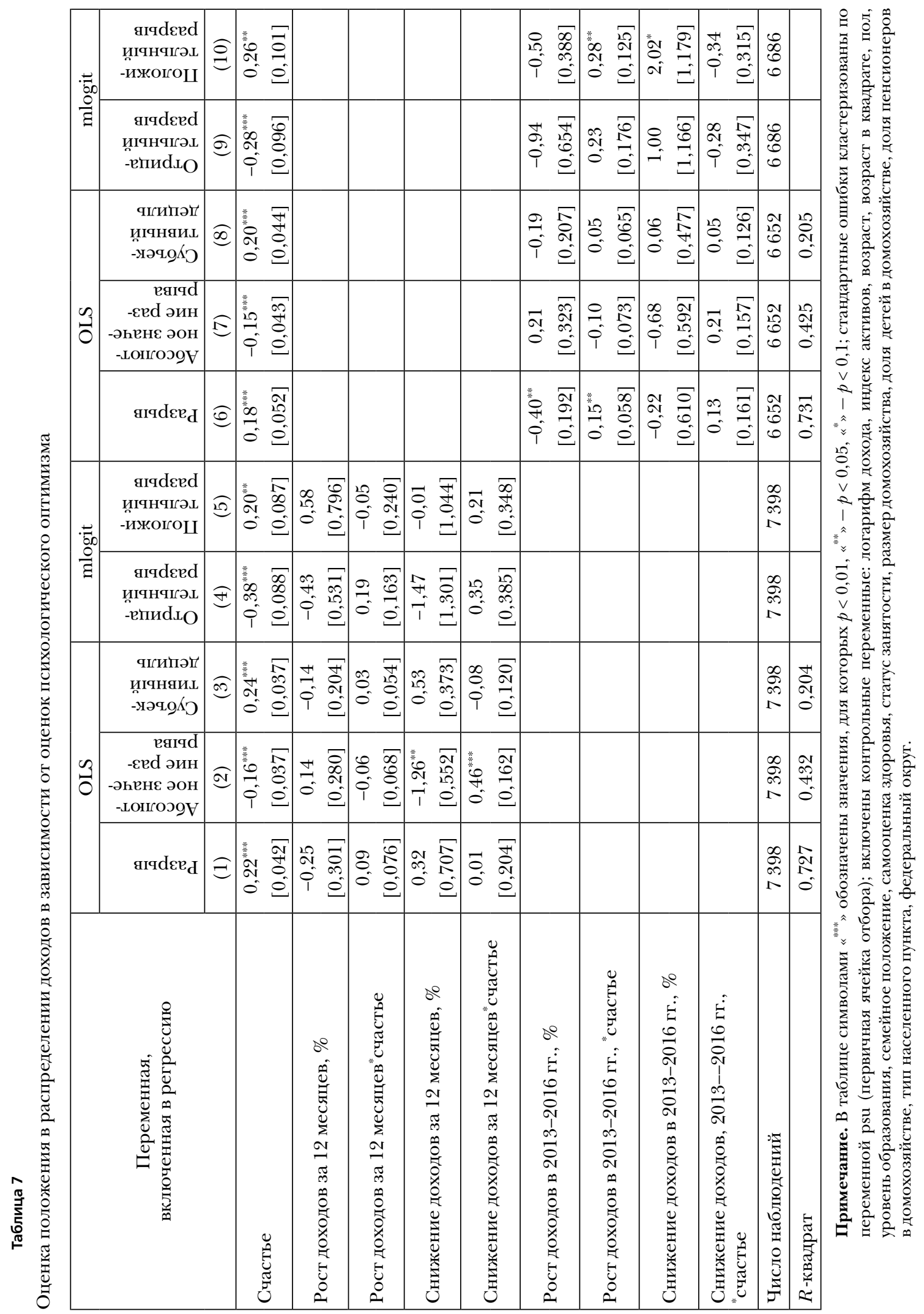




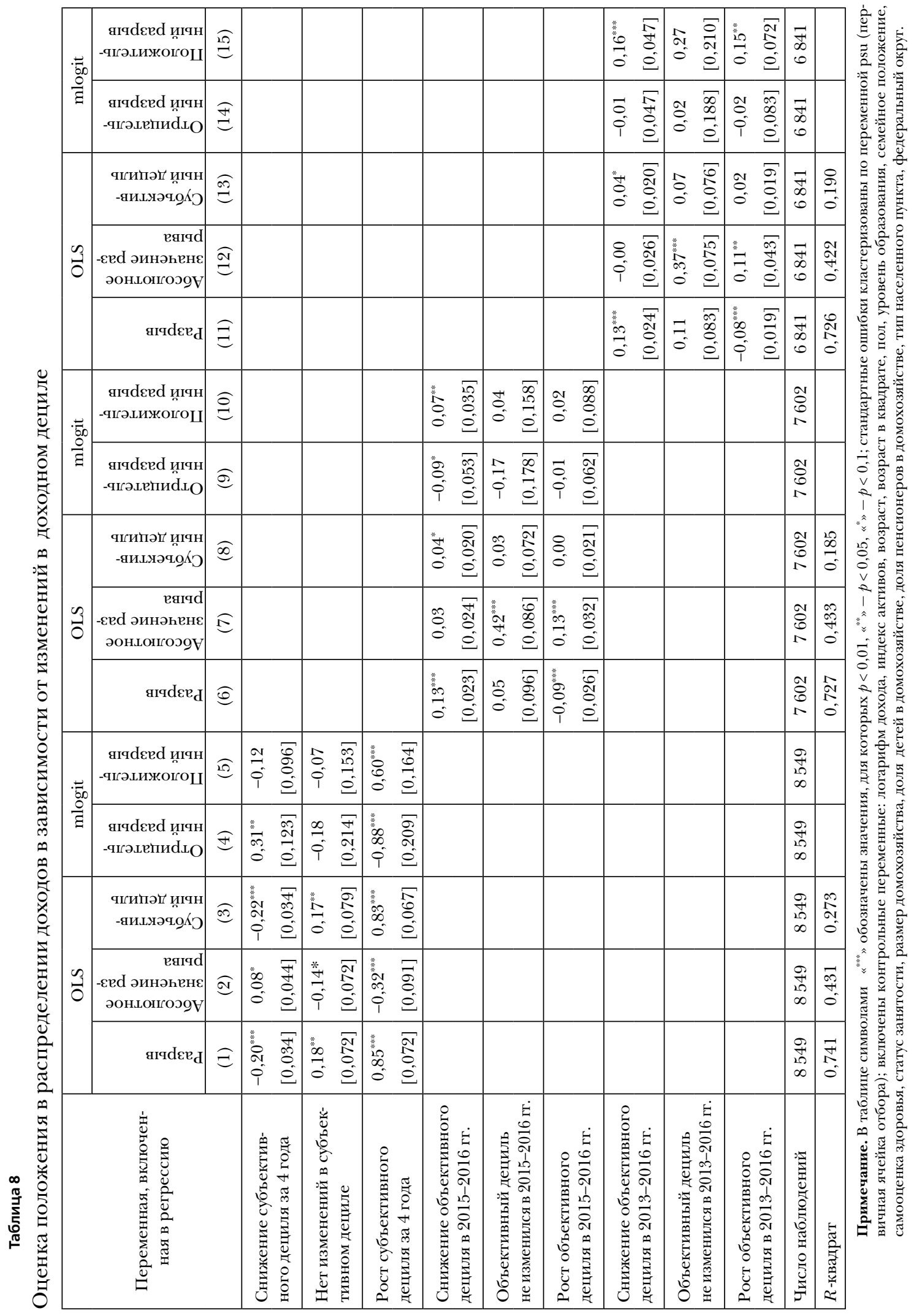


7.1. Объективное и субъективное изменение благосостояния

Как показывают результаты, приведенные в табл. 6, восприятие динамики благосостояния коррелирует с восприятием текущего положения в распределении благосостояния. Ухудшение материального положения значимо снижает значение субъективного дециля (коэффициент $\left.-0,58^{* * *}\right)$. При этом разрыв как простая разность децилей становится более отрицательным, а его абсолютная величина возрастает. Вероятность отрицательного разрыва растет, а положительного падает. При положительной субъективной динамике материального положения разрыв с учетом знака увеличивается, абсолютный практически не меняется. Поскольку одни и те же индивидуальные особенности человека могут формировать обе (динамическую и статическую) оценки материального благополучия, то это создает корреляцию между ними.

Далее в табл. 6 приводятся связи разрыва с динамикой доходов, определяемой по объективным данным. Оказывается, что изменение доходов не связано статистически значимо с восприятием своего текущего положения. Единственный значимый результат - рост вероятности положительного разрыва с ростом изменений дохода, причем как в сторону роста, так и в сторону снижения.

В табл. 7 содержатся оценки, модифицированные интеракцией показателей динамики доходов и прокси-переменной для оценки психологического оптимизма. В случае положительных долгосрочных изменений (2013-2016 гг.) более счастливые респонденты имеют более положительный разрыв (табл. 7, столбец 6). Это можно интерпретировать таким образом, что «оптимисты» склонны реагировать на положительные сигналы и ставить себя выше на субъективной децильной шкале.

Табл. 8 оперирует показателями относительной (а не абсолютной) динамики доходов. Субъективное восприятие изменения своего доходного дециля (по сравнению с тем децилем, который был четыре года назад) связано с текущим восприятием. Увеличение субъективного дециля значимо сдвигает вправо текущий субъективный дециль, повышает величину разрыва (с учетом знака) и снижает абсолютный разрыв. Его (субъективного дециля) уменьшение имеет обратное влияние и также значимо. При этом мы видим явную асимметрию между влиянием роста и снижения: первое оказывается намного сильнее. Это возможно в том случае, если рост субъективного дециля чаще отмечают те, кто переоценивает свое положение и в этом смысле являются «оптимистами».

Следующие две части табл. 8 имеют дело с объективными измерителями изменений в объективном дециле. Они показывают в целом обратную картину: с ростом объективного дециля (за год или три) текущий субъективный дециль не меняется (коэффициенты незначимы), разрыв становится более отрицательным (коэффициенты значимы 


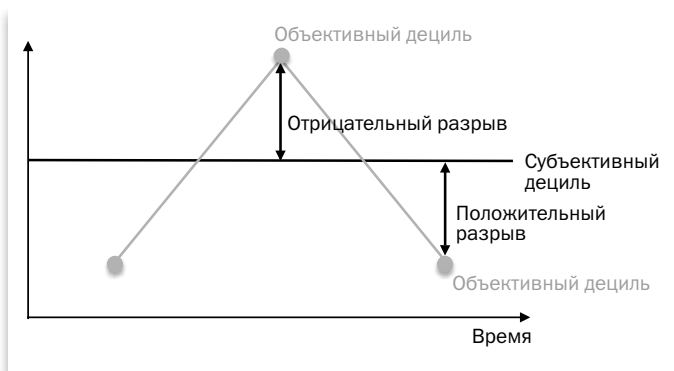

Puc. 3

Схема динамики субъективного и объективного деиилей и отрицательны), а абсолютный увеличивается (коэффициенты значимы и положительны). Со снижением объективного дециля мы видим только увеличение разрыва. Подобное возможно в том случае, когда индивиды переоценивают свое текущее положение, т.е. если $\left(X_{\text {perc }}-X_{a c t}\right)>0$. В нашем случае это, как правило, не так.

Итак, ни краткосрочная (2015-2016 гг.), ни долгосрочная (2013-2016 гг.) динамики объективного дециля не влияют статистически значимо на субъективное положение и неожиданным образом влияют на разрыв: движение объективного дециля (вверх или вниз) связано с изменением разрыва в противоположном направлении.

Такой результат возможен, если субъективное положение индивидов стабильно во времени и слабо зависит от изменений в фактическом положении. Как мы видели выше, представления индивидов практически не зависят от объективных изменений в доходах. Если такие изменения приводят к перемещению индивида в распределении доходов, то он это не ощущает. Поскольку в среднем индивиды недооценивают свое положение, то, перемещаясь вниз, они приближаются к своей оценке, а перемещаясь вверх - отдаляются от нее. Иллюстрация того, как это может происходить, представлена на рис. 3. Объективные доходы колеблются вокруг (постоянных) субъективных доходов. Тогда движение вверх по объективной лестнице доходов сужает разрыв или даже превращает его в отрицательный, и наоборот.

\section{8. Заключение}

Политики и чиновники часто видят в неравенстве угрозу социальной и политической стабильности, т.е. угрозу самим себе. Они предполагают, что люди в условиях высокого неравенства более склонны к протестным требованиям разного рода. Также интерпретируют влияние неравенства и многие теории. Но что если люди не знают, какое неравенство существует на самом деле и находятся в плену собственных и часто неверных представлений? Именно эти представления и могут формировать действия и ожидания. Но в этом случае связь между объективным неравенством и поведением оказывается разорванной.

В этой работе мы эмпирически исследуем одно из измерений субъективно воспринимаемого неравенства - как жители России воспринимают свое место в распределении населения по доходу. Мы отвечаем на два вопроса: как это восприятие отличается от реальности и каковы детерминанты складывающегося расхождения. 
Чтобы ответить на эти вопросы, мы обращаемся к эмпирическим данным, которые содержат как вопрос о субъективной оценке респондентами своего места в распределении благосостояния, так и объективные показатели положения домохозяйств, а также широкий набор индивидуальных и семейных характеристик респондентов. Мы сравниваем ответ о субъективном дециле с оценками объективного дециля, к которому принадлежит респондент. Затем мы пытаемся объяснить расхождение между этими мерами.

Расчеты показывают, что размер различий между субъективным и объективным положениями респондентов в среднем составляет 2 дециля (а если не учитывать знак различия, то 3), имеют место как отрицательные, так и положительные отклонения. Только один из десяти респондентов правильно оценивает свое положение. Две трети респондентов недооценивают, а каждый пятый - переоценивает дециль, к которому он принадлежит.

При исследовании факторов, влияющих на ошибки восприятия, мы особое внимание уделяем так называемому туннельному эффекту (сигналу о возможной позитивной динамике). Являются ли прошлые изменения в положении на шкале доходов фактором, влияющим на размер ошибки? Мы показываем, что субъективные оценки мобильности вдоль шкалы доходов имеют значение, а объективные - практически нет. При этом субъективные оценки преломляются через личностные характеристики индивидов, в результате чего могут усиливаться (положительные у оптимистов или отрицательные у пессимистов). В целом наши результаты свидетельствуют о стабильности оценок индивидами своего положения в распределении доходов во времени и их слабой связи с фактическим доходом и его прошлой динамикой.

Россия считается страной с высоким неравенством доходов, что подтверждается сравнительным анализом стандартных мер дифференциации, которые, в свою очередь, строятся на данных объективной статистики. Чем выше фактическое неравенство, тем тяжелее должны быть концы распределения за счет провала в его середине. И хотя большинство россиян уверены в том, что они живут в стране с очень неравным распределением доходов, они склонны ставить себя в середину распределения. В этом содержится противоречие.

Понимание последствий дифференциации доходов предполагает исследование как ее объективных оценок, так и субъективных представлений. Что бы ни показывала самая надежная статистика, обычные люди ею мало интересуются и имеют свои представления об окружающей их реальности. Эти представления часто оказываются более важным фактором, влияющим на поведение, чем самые точные цифры из статистических ведомств. Хотя именно они движут людьми, мы пока знаем слишком мало о том, как они формируются и как соотносятся с реальностью. Наша статья - скромный шаг в этом направлении. 


\section{ЛИТЕРАТУРА / REFERENCES}

Alesina A., Angeletos G.M. (2005). Fairness and redistribution: US vs. Europe. American Economic Review, 95, 913-935.

Alesina A., Fuchs-Schündeln N. (2007). Goodbye Lenin (or not)? The effect of communism on people's preferences. American Economic Review, 97, 4, 1507-1528.

Alesina A., Giuliano P. (2011). Preferences for redistribution. In: Handbook of social economics, 1, 9-131). North-Holland.

Alesina A., La Ferrara E. (2005). Preferences for redistribution in the land of opportunities. Journal of Public Economics, 89, 5-6, 897-931.

Benabou R., Ok E.A. (2001). Social mobility and the demand for redistribution: The POUM hypothesis. The Quarterly Journal of Economics, 116, 2, 447-487.

Benabou R., Tirole J. (2006). Belief in a just world and redistributive politics. The Quarterly Journal of Economics, 121, 2, 699-746.

Bublitz E. (2017). Misperceptions of income distributions: Cross-country evidence from a randomized survey experiment. LIS Working Paper Series, No. 694.

Chambers J.R., Swan L.K., Heesacker M. (2014). Better off than we know: Distorted perceptions of incomes and income inequality in America. Psychological Science, 25, 2, 613-618.

Choi G. (2019). Revisiting the redistribution hypothesis with perceived inequality and redistributive preferences. European Journal of Political Economy, 58, 220-244.

Clark A.E., d'Ambrosio C. (2015). Attitudes to income inequality: Experimental and survey evidence. In: Handbook of income distribution. Elsevier, 2, 1147-1208.

Cruces G., Perez-Truglia R., Tetaz M. (2013). Biased perceptions of income distribution and preferences for redistribution: Evidence from a survey experiment. Journal of Public Economics, 98, 100-112.

Denisova I. (2007). Entry to and exit from poverty in Russia: Evidence from longitudinal data. CEFIR/NES Working Paper \# WP/2007/077. Moscow: New Economic School.

Eriksson K., Simpson B. (2012). What do Americans know about inequality? It depends on how you ask them. Judgment and Decision Making, 7, 6, 741-745.

Fernández-Albertos J., Kuo A. (2018). Income perception, information, and progressive taxation: Evidence from a survey experiment. Political Science Research and Methods, 6, 1, 83-110.

Gimpelson V., Treisman D. (2018). Misperceiving inequality. Economics $\mathcal{E}$ Politics, 30, $1,27-54$.

Hadavand A. (2018). Misperceptions: An analysis of subjective economic inequality. J.A. Bishop, J.G. Rodríguez (eds.). Inequality, taxation and intergenerational transmission (research on economic inequality. Vol. 26. Emerald Publishing Limited, 247-281.

Hirschman A.O. (1973). The changing tolerance for income inequality in the course of economic development, with a mathematical appendix by Michael Rothschild. Quarterly Journal of Economics, 87, 544-566.

Hu A. (2017). On the relationship between subjective inequality and generalized trust. Research in Social Stratification and Mobility, 49, 11-19. 
Jäntti M., Kanbur R., Nyyssölä M., Pirttilä J. (2014). Poverty and welfare measurement on the basis of prospect theory. Review of Income and Wealth, 60, 1, 182-205.

Justino P., Martorano B. (2016). Inequality, distributive beliefs and protests: A recent story from Latin America. Available at: https://opendocs.ids.ac.uk/opendocs/ handle $/ 20.500 .12413 / 11559$

Karadja M., Mollerstrom J., Seim D. (2017). Richer (and holier) than thou? The effect of relative income improvements on demand for redistribution. Review of Economics and Statistics, 99, 2, 201-212.

Knell M., Stix H. (2017). Perceptions of inequality. Working Paper Series of the Oesterreichische Nationalbank No. 216.

Kuhn A. (2011). In the eye of the beholder: Subjective inequality measures and individuals' assessment of market justice. European Journal of Political Economy, 27, $4,625-641$.

Kuhn A. (2015). The individual perception of wage inequality: A measurement framework and some empirical evidence. IZA Discussion Paper No. 9579.

Kuziemko I., Norton M.I., Saez E., Stantcheva S. (2015). How elastic are preferences for redistribution? Evidence from randomized survey experiments. American Economic Review, 105, 4, 1478-1508.

Lyubomirsky S., Ross L. (1997) Hedonic consequences of social comparison: A contrast of happy and unhappy people. Journal of Personality and Social Psychology, $73,6,1141-1157$.

Lyubomirsky S., Tucker K.L. (1998). Implications of individual differences in subjective happiness for perceiving, interpreting, and thinking about life events. Motivation and Emotion, 22, 2, 155-186.

Meltzer A.H., Richard S.F. (1981). A rational theory of the size of government. Journal of Political Economy, 89, 5, 914-927.

Niehues J. (2014). Subjective perceptions of inequality and redistributive preferences: An international comparison. Cologne Institute for Economic Research. IWTRENDS Discussion Paper, 2.

Norton M.I., Ariely D. (2011). Building a better America - one wealth quintile at a time. Perspectives on Psychological Science, 6, 1, 9-12.

Novokmet F., Piketty T., Zucman G. (2018). From Soviets to oligarchs: Inequality and property in Russia 1905-2016. The Journal of Economic Inequality, 16, 2, 189-223.

Osberg L., Bechert I. (2016). Social values for equality and preferences for state intervention in the USA and Elsewhere. Available at: http:/ / www.ecineq.org/ecineq_nyc17/ FILESx2017/CR2/p89.pdf

Osberg L., Smeeding T. (2006). "Fair" inequality? Attitudes toward pay differentials: the United States in comparative perspective. American Sociological Review, 71, $3,450-473$.

Page L., Goldstein D.G. (2016). Subjective beliefs about the income distribution and preferences for redistribution. Social Choice and Welfare, 47, 1, 25-61.

Ravallion M., Lokshin M. (1999). Subjective economic welfare. The World Bank.

Ravallion M., Lokshin M. (2001). Identifying welfare effects from subjective questions. Economica, 68, 271, 335-357. 
Ravallion M., Lokshin M. (2002). Self-rated economic welfare in Russia. European Economic Review, 46, 8, 1453-1473.

Stillman S. (2001). The response of consumption in Russian households to economic shocks. IZA Discussion Paper, 411.

Wall M., Johnston D. (2008). Counting heads or counting televisions: Can asset-based measures of welfare assist policy-makers in Russia? Journal of Human Development, 9, 1, 131-147.

Поступила в редакиию 22.08.2019

Received 22.08.2019

\section{V.E. Gimpelson}

Centre for labour market studies at National Research University Higher

School of Economics, Moscow, Russia

\section{E.M. Chernina}

Centre for labour market studies at National Research University Higher

School of Economics, Moscow, Russia

\section{How we perceive our place in income distribution and how the perceptions deviate from reality}

Abstract. We explore how individuals perceive their location in the income distribution and how these perceptions correspond to estimates provided by objective statistical data. Then we try to explain the deviations paying a special attention to past experience of income mobility, individuals may have, and to such psychological traits as feelings of optimism / pessimism. In our search for answers we use RLMS-HSE data for, 2016. In this round of the survey, respondents were asked to assign themselves to an income decile they belonged. We compare this self-estimate with the actual decile to which the household belongs given its income statistically measured. As some previous studies, we find systematic biases in perceptions. Individuals tend to put themselves in the middle of the distribution and perceive themselves relatively poorer as they in fact are. Our analysis suggests that the subjective place in the distribution depends neither on actual income level, nor its dynamics. General optimism in life and the perception that there have been positive changes in their life, tend to rise the subjective decile.

Keywords: income distribution, perceptions, inequality.

JEL Classification: D31, D63, I31.

DOI: $10.31737 / 2221-2264-2020-46-2-2$ 